\title{
Systemic effects of phytoecdysteroids on the cabbage aphid Brevicoryne brassicae (Sternorrhyncha: Aphididae)
}

\author{
Roman PAVELA ${ }^{1}$, Juraj HARMATHA ${ }^{2}$, Martin BÁRNET ${ }^{1}$ and Karel VOKÁĆ ${ }^{2}$ \\ ${ }^{1}$ Research Institute of Crop Production, Drnovská 507, 16106 Praha 6 - Ruzyně, Czech Republic; e-mail: pavela@vurv.cz \\ ${ }^{2}$ Institute of Organic Chemistry and Biochemistry, Academy of Sciences of the Czech Republic, Flemingovo nám. 2, 16610 Praha 6, \\ Czech Republic; e-mail: harmatha@uochb.cas.cz
}

Key words. Ecdysteroid, phytoecdysteroid, Leuzea carthamoides, cabbage aphid, Brevicoryne brassicae, systemic action, fecundity, mortality, plant-insect interaction

\begin{abstract}
The systemic effects of phytoecdysteroids were investigated by applying tested compounds to the roots of the rape plants. Evaluation of the effects was based on mortality, longevity, rate of development and fecundity of the cabbage aphid (Brevicoryne brassicae L., Sternorrhyncha: Aphididae) feeding on the shoot of the treated plants. The major ecdysteroid compounds tested were natural products isolated from a medicinal plant Leuzea carthamoides DC (Willd.) Iljin (Asteraceae): 20-hydroxyecdysone (20E), ajugasterone $\mathrm{C}$ (ajuC) and polypodine B (polyB). The compounds were tested in two concentrations $(0.07 \mathrm{and} 0.007 \mathrm{mg} / \mathrm{ml}) \mathrm{in}$ water. In addition, we have also investigated the systemic effects of a special Lc-Ecdy 8 fraction isolated from L. carthamoides, which contained $20 \mathrm{E}$, ajuC and polyB and at least six other minor compounds in addition to the above indicated ecdysteroids. HPLC analysis of the Lc-Ecdy 8 fraction indicated the presence of makisterone A and inokosterone in minor quantities. It appeared that all ecdysteroid compounds tested, with the exception of the most common, 20E, decreased the fecundity of cabbage aphids which fed on the contaminated rape plants. The mortality of larvae and adults significantly increased on plants treated with the Lc-Ecdy 8 fraction, and with ajuC or polyB compounds containing structural substituents in rather unusual positions. The most common phytoecdysteroid, 20E, with the typical and characteristic ecdysteroid structure, was the best tolerated of all phytoecdysteroi ds tested.
\end{abstract}

\section{INTRODUCTION}

Ecdysteroids are polyhydroxylated steroid compounds with specific structural features (Lafont, 1998) and with typical moulting / metamorphosis hormone activities in arthropods (Bergamasco \& Horn, 1980). Structural analogues of the insect moulting hormone ecdysone have also been discovered in plants (e.g. Galbraith \& Horn, 1966; Nakanishi et al., 1966; Jizba et al., 1967). Subsequent research has revealed that phytoecdysteroid occurrence is widespread (Dinan, 2004a). More than 330 different ecdysteroids have been identified in vascular plants, fungi, algae, non-arthropod invertebrates and marine organisms (Lafont et al., 2002).

Phytoecdysteroids, plant ecdysteroid analogues, have been found in representatives of more than 100 vascular plant families (Bergamasco \& Horn, 1983). However, the rationale behind the distribution of ecdysteroids in the plant kingdom, as well as the role(s) of these compounds in plants, is still to be elucidated. According to the most accepted hypothesis, phytoecdysteroids are allelochemical toxins and antifeedants contributing to the deterrence of non-adapted phytophagous insects (Camps, 1991; Lafont et al., 1991; Adler \& Grebenok, 1999; Dinan, 2001). The increasing number of investigations on plant-insect chemical interactions in the last few decades has unveiled the potential for utilizing secondary plant metabolites, or allelochemicals, as pest control agents. An alternative approach to crop protection based on ecdysteroids is to modify ecdysteroid levels and/or profiles in crop plants (most of which do not contain ecdysteroids) to enhance protection against invertebrate predators. This is based on the assumption that ecdysteroids contribute significantly to plant protection, at least against the nonadapted herbivores. There is increasing evidence that this is true, except for certain polyphagous insect pests which are unaffected by diets containing very high concentrations of ecdysteroids (Dinan et al., 1998).

The effect of phytoecdysteroids on different organisms has been extensively studied in various experimental models (Dinan, 2004b). The selection of compounds used for such studies mostly depends on their availability from a rather narrow selection of plants rich in ecdysteroids and diverse in their quantity or structural variability (Lafont et al., 1991). Leuzea carthamoides (Willd.) DC., [syn. Rhaponticum carthamoides (Willd.) Iljin] was selected as the best source of the required compounds for our study. The plant is endemic to southern Siberia, but now is also cultivated in Eastern Europe as a promising medicinal plant. The composition of arthropods within the trial plantation of $L$. carthamoides is typical of most of the introduced plant species. Leuzea is host to a large range of oligo- and polyphagous insects, including mites (Zelený et al., 1997).

Extracts of this plant contain a wide variety of isoprenoid and polyphenolic compounds. Earlier reports focused mainly on the content of flavonoids and sesquiterpene $\alpha$-exomethylene- $\gamma$-lactones. Later reports turned their main attention towards the content of ecdysteroids. The roots and, later, also the seeds were used as a rich source of major phytoecdysteroids, especially 20hydroxyecdysone, ajugasterone $\mathrm{C}$, polypodine $\mathrm{B}$, and also 
a set of their structural analogues (Píš et al., 1994; Vokáč et al., 2002). We decided to use a selection of these ecdysteroids for assessing their activity on aphids. Insecticidal effects and the influence of plant ecdysteroids on aphids have so far not been experimentally studied. Generally, the cabbage aphid, as well as other mono- and oligophagous insects, are sensitive to biochemical changes in their host plants and could react to these changes in a positive or negative way. Our interest was to determine the influence of ecdysteroids supplied to the host plant on an aphid species with an assumed high sensitivity to these compounds.

The cabbage aphid (Brevicoryne brassicae L.), is an economically important pest of the Brassicaceae family in general and of the genus Brassica in particular. The plants of family Brassicaceae generally do not contain ecdysteroids (Dinan, 2004a). However, the leaf ecdysteroid content analysis of treated plants demonstrated that the ecdysteroids were translocated from the culture medium to the leaf without any apparent change in composition (Melé et al., 1992). Such an in vitro technique appears particularly appropriate in bioassays taking advantage of the feeding mechanism of sucking insects (Melé et al., 1992, Pavela et al., 2004). Therefore, we investigated the effects of several selected ecdysteroids in various concentrations and also one crude crystalline ecdysteroid fraction isolated from $L$. carthamoides. The compounds were applied hydroponically through the roots of the rape plants in order to determine their effect on the mortality, development and fecundity of cabbage aphids.

\section{MATERIAL AND METHODS}

Plants. The experimental rape plants (Brassica napus subsp. napus) were grown in flowerpots (diameter $30 \mathrm{~cm}$ ), using a standard soil substrate for sowing. The flowerpots were kept in climatic boxes under a $16 \mathrm{~L}: 8 \mathrm{D}$ regime, temperature $22 \pm 0.5^{\circ} \mathrm{C}$ and relative humidity $60-80 \%$. Five days after germination, when secondary leaves began to develop in $60-70 \%$ of the seedlings, the plants were removed from the soil, the substrate was cleaned off their roots with running water and they were used for the experiment.

Insects. Cabbage aphids (Brevicoryne brassicae L., Sternorrhyncha: Aphididae) were obtained from a laboratory colony reared on rape plants (Brassica napus subsp. napus). 100 winged females from the colony were introduced onto rape plants in a cage $(20 \times 50 \times 50 \mathrm{~cm})$. Females were removed from the plants after $12 \mathrm{~h}$, and resulting progeny were used for the experiment. The colonies were maintained in an insectary at 22 $\pm 1^{\circ} \mathrm{C}, 60-70 \% \mathrm{RH}$ and $16 \mathrm{~L}: 8 \mathrm{D}$. Four experiments were performed:

Nymphs. $1^{\text {st }}$ instar nymphs $(<12 \mathrm{~h}$ old $)$ were transferred to treated plants and kept there until the last ecdysis. The adults were then introduced to the untreated (or control) plants.

Adults. Newly-emerged adults were introduced to the treated plants.

Nymphs and adults. Aphids fed on treated plants during their whole life.

Control. Aphids fed on control plants during their whole life.

We investigated the effects of phytoecdysteroids applied hydroponically through the roots of plants on the mortality, development and fecundity of the aphids. The aphids were
TABLE 1. Content of ecdysteroids in the crystalline fraction of Lc-Ecdy 8 as determined by HPLC analysis (Píš et al., 1994 and Vokáč et al., 2002). For chemical structures see Lafont et al. (2002).

\begin{tabular}{lc}
\hline Compound & Content in \% \\
\hline 20-hydroxyecdysone (20E) & 45.4 \\
polypodine B (polyB) & 9.0 \\
Inokosterone & 2.4 \\
makisteron A & 5.2 \\
ajugasteron C (ajuC) & 19.2 \\
unidentified 1 compound & 2.6 \\
unidentified 4 compounds & all in range 1.0-1.5 \\
unidentified 18 compounds & all under 1.0 \\
\hline
\end{tabular}

monitored every day. Mortality and ecdysis were recorded for the nymphs, while mortality (longevity) and fecundity (number of nymphs produced) were recorded for adults.

Chemicals. A crystalline ecdysteroid fraction isolated from the root extract of Leuzea carthamoides (Lc-Ecdy 8) was used for our experiments. Its composition was analyzed and the main constituents identified by high performance liquid chromatography (HPLC) using authentic standard compounds as reference samples. The composition of this fraction is indicated in Table 1. The major ecdysteroid constituents of this fraction, 20hydroxyecdysone $(20 \mathrm{E})$, ajugasterone $\mathrm{C}(\mathrm{ajuC})$ and polypodine B (polyB) were also tested as individual samples. Their HPLC purity was: $97.5 \%$ for $20 \mathrm{E}, 95.3 \%$ for $\mathrm{AjuC}$ and $99.2 \%$ for polyB. Makisterone A and inokosterone, detected in fraction LcEcdy 8 in only minor quantities (5.2\% and $2.4 \%$, respectively), were not tested individually. The other unidentified minor constituents of this fraction (with contents higher than 1\%) were, according to their UV spectra (recorded by a Diode Array Detector), most probably also ecdysteroids. The structural differences between the three main ecdysteroids found are the number and positions of the hydroxyl groups (see Fig. 1). Aju C is isomeric to $20 \mathrm{E}$ with a missing hydroxyl in position 25 and with an additional one in position 11 (in the alpha configuration). PolyB is a derivative of $20 \mathrm{E}$ with one additional hydroxyl in position 5 (in the beta configuration). The minors: makisterone $\mathrm{A}$ and inokosterone are also closely related struc-<smiles>[R2]C1C[C@]2(C)[C@@H]([C@](C)(O)[C@@H](O)CCC([R3])(C)C)CC[C@]2(O)C2=CC(=O)[C@]3([R3])C[C@H](O)[C@@H](O)C[C@]3(C)C21</smiles>

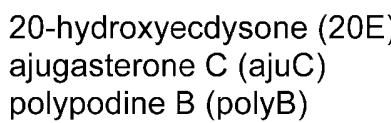

$\begin{array}{lll}\mathbf{R}_{\mathbf{1}} & \mathbf{R}_{\mathbf{2}} & \mathbf{R}_{\mathbf{3}} \\ \mathrm{H} & \mathrm{H} & \mathrm{OH} \\ \mathrm{H} & \mathrm{OH} & \mathrm{H} \\ \mathrm{OH} & \mathrm{H} & \mathrm{OH}\end{array}$

Fig. 1. Chemical structures of the major ecdysteroid constituents present in Leuzea carthamoides and in the crystalline ecdysteroid fraction Lc-Ecdy 8 (for composition see Table 1). 
TABLE 2 . Effect of ecdysteroids on aphid mortality. * Mortality time in days, when aphid population reached $50 \%\left(\mathrm{LT}_{50}\right)$ and $90 \%\left(\mathrm{LT}_{90}\right)$ mortality level. ${ }^{* *}$ Efficacy index (in \%) of ecdysteroids related to the control. $\mathrm{r}$ - Regression reliability .

\begin{tabular}{|c|c|c|c|c|c|c|c|c|c|}
\hline & \multicolumn{3}{|c|}{ Nymphs } & \multicolumn{3}{|c|}{ Adults } & \multicolumn{3}{|c|}{ Nymphs and adults } \\
\hline & $\mathrm{LT}_{50}$ & $\mathrm{LT}_{90}$ & $\mathrm{r}$ & $\mathrm{LT}_{50}$ & $\mathrm{LT}_{90}$ & $\mathrm{r}$ & $\mathrm{LT}_{50}$ & $\mathrm{LT}_{90}$ & $\mathrm{r}$ \\
\hline Control & 20.45 & 28.03 & 0.96 & 13.64 & 21.03 & 0.96 & 20.45 & 28.03 & 0.96 \\
\hline Lc-Ecdy $8(0.7 \mathrm{mg} / \mathrm{ml})$ & $\begin{array}{c}7.75^{*} \\
(62.1)^{* *}\end{array}$ & $\begin{array}{l}12.33 \\
(56.0)\end{array}$ & 0.95 & $\begin{array}{c}7.99 \\
(41.4)\end{array}$ & $\begin{array}{l}12.73 \\
(39.5)\end{array}$ & 0.98 & $\begin{array}{c}6.72 \\
(67.1)\end{array}$ & $\begin{array}{l}10.19 \\
(63.6)\end{array}$ & 0.91 \\
\hline Lc-Ecdy $8(0.07 \mathrm{mg} / \mathrm{ml})$ & $\begin{array}{l}13.26 \\
(35.2)\end{array}$ & $\begin{array}{l}23.23 \\
(17.1)\end{array}$ & 0.89 & $\begin{array}{c}9.45 \\
(30.7)\end{array}$ & $\begin{array}{l}14.43 \\
(31.4)\end{array}$ & 0.93 & $\begin{array}{l}10.50 \\
(48.7)\end{array}$ & $\begin{array}{l}17.23 \\
(38.5)\end{array}$ & 0.88 \\
\hline $20 \mathrm{E}(0.7 \mathrm{mg} / \mathrm{ml})$ & $\begin{array}{l}20.81 \\
(-1.8)\end{array}$ & $\begin{array}{c}33.31 \\
(-18.8)\end{array}$ & 0.86 & $\begin{array}{c}9.08 \\
(33.4)\end{array}$ & $\begin{array}{l}18.30 \\
(13.0)\end{array}$ & 0.91 & $\begin{array}{l}15.93 \\
(22.1)\end{array}$ & $\begin{array}{c}25.39 \\
(9.4)\end{array}$ & 0.97 \\
\hline $20 \mathrm{E}(0.07 \mathrm{mg} / \mathrm{ml})$ & $\begin{array}{l}19.65 \\
(3.9)\end{array}$ & $\begin{array}{c}32.43 \\
(-15.7)\end{array}$ & 0.97 & $\begin{array}{l}13.34 \\
(2.2)\end{array}$ & $\begin{array}{l}20.38 \\
(3.1)\end{array}$ & 0.93 & $\begin{array}{l}19.37 \\
(5.3)\end{array}$ & $\begin{array}{c}27.05 \\
(3.5)\end{array}$ & 0.95 \\
\hline ajuC $(0.07 \mathrm{mg} / \mathrm{ml})$ & $\begin{array}{l}12.88 \\
(37.0)\end{array}$ & $\begin{array}{l}21.96 \\
(21.7)\end{array}$ & 0.95 & $\begin{array}{c}5.92 \\
(56.6)\end{array}$ & $\begin{array}{c}9.55 \\
(54.6)\end{array}$ & 0.96 & $\begin{array}{c}6.93 \\
(66.1)\end{array}$ & $\begin{array}{l}10.28 \\
(63.3)\end{array}$ & 0.92 \\
\hline polyB $(0.07 \mathrm{mg} / \mathrm{ml})$ & $\begin{array}{l}10.55 \\
(48.4)\end{array}$ & $\begin{array}{l}16.42 \\
(41.4)\end{array}$ & 0.94 & $\begin{array}{c}8.76 \\
(35.8)\end{array}$ & $\begin{array}{l}14.16 \\
(32.7)\end{array}$ & 0.92 & $\begin{array}{l}10.23 \\
(50.0)\end{array}$ & $\begin{array}{l}17.65 \\
(37.0)\end{array}$ & 0.96 \\
\hline
\end{tabular}

turally to $20 \mathrm{E}$ (makisterone with an additional methyl group in position 24, and inokosterone with a hydroxyl at position 26 instead of 25). For their complete structures see Ecdybase (Lafont et al., 2002).

Method. The method published by Gelbič et al. (1984) and modified by Pavela et al. (2004) was used in this experiment. The roots of the plants were put into $10 \mathrm{ml}$ test tubes containing $6 \mathrm{ml}$ of water without phytoecdysteroids or with Lc-Ecdy 8 , 20E, ajuC and/or polyB solution at the following concentrations: $0.07 \mathrm{mg} \cdot \mathrm{ml}^{-1}$ (all phytoecdysteroids) and 0.7 mg. $\mathrm{ml}^{-1}$ (phytoecdysteroids Lc-Ecdy 8 and 20E). The solutions were regenerated every three days. The test tubes were placed individually in separate plastic pots. The plants were kept in climatic boxes under artificial lighting $16 \mathrm{~L}: 8 \mathrm{D}$, temperature $22 \pm$ $0.5^{\circ} \mathrm{C}$ and relative humidity $60-70 \%$. The plastic pots with the plants were kept at the above-specified conditions for period of $24 \mathrm{~h}$ before introducing cabbage aphid nymphs. A single nymph was put on every plant tip using a small brush. Seven aphids were used for each treatment in each of three replications. The nymphs and subsequent adults were checked daily until the experiment was finished. The experiment was carried out under conditions identical to those applied before the introduction of nymphs.

Data analyses and statistics. In order to compare the effect of ecdysteroids on aphid mortality, means of linear regression were calculated from the obtained data, valid for periods when the tested aphid population reached $50 \%\left(\mathrm{LT}_{50}\right)$ and $90 \%\left(\mathrm{LT}_{90}\right)$ mortality, respectively. The efficacy index of the ecdysteroids (in relation to the control) was calculated from the observed data using the equation: $\mathrm{EM}=(\mathrm{LTt} / \mathrm{LTc}) \times 100$, where $\mathrm{LTc}$ and LTt are the $\mathrm{LT}_{50}$ and/or $\mathrm{LT}_{90}$ in control and treatment, respectively.

Data for the development, longevity and fertility were subjected to analysis of variance (ANOVA). Differences between treatments were determined by Tukey's test. Differences among means were considered significant at $\mathrm{P} \leq 0.05$.

\section{RESULTS}

\section{Mortality}

Nymphs

All ecdysteroids, except 20E, increased the mortality of aphids that sucked on treated plants during their nymphal stage compared to the control (Table 2). The most signifi- cant mortality increase was observed with ecdysteroid mixture Lc-Ecdy 8, when $\mathrm{LT}_{50}$ and $\mathrm{LT}_{90}$ reached 7.75 and 12.33 days, respectively. This was $62 \%$ and $56 \%$ less time, respectively, than required for $50 \%$ and $90 \%$ mortality, compared to the control. The mortality course caused by pure ecdysteroids was faster with the polyC, when $\mathrm{LT}_{50}$ and $\mathrm{LT}_{90}$ were observed at 10.55 and 16.42 days, respectively. This was $48.4 \%$ and $41.4 \%$ less time, respectively, than required for $50 \%$ and $90 \%$ mortality, compared to the control (Table 2). 20E had no influence on the rise in mortality comparing with the control. On the contrary, the times required to reach $90 \%$ mortality, for concentrations of 0.7 and $0.07 \mathrm{mg} / \mathrm{ml}$, were comparable to the control, $18.8 \%$ and $15.7 \%$ longer, respectively. The other data are indicated in Table 2.

\section{Adults}

As long as the aphids had sucked on the treated plants by the end of their ecdysis (i.e., only as adults), mortality was observed with all tested ecdysteroids (Table 2). The fastest course of mortality was observed with ajuC, when $50 \%\left(\mathrm{LT}_{50}\right)$ and $90 \%\left(\mathrm{LT}_{90}\right)$ mortality was 5.92 and 9.55 days, respectively, recorded from the aphids' introduction to the treated plant. These were $56.6 \%$ and $54.6 \%$ shorter times, respectively, compared to the control. The mortality compared to the control group also increased with 20E; nevertheless, this effect was proven only at higher concentrations. Lower concentrations had no effect.

\section{Nymphs and adults}

The course of mortality for the aphids sucking during their whole life on plants corresponded with the results obtained in the previous two tests. A partially cumulative effect for some ecdysteroids was observed in this case. The most significantly shortened life spans for $50 \%$ and $90 \%$ aphid mortality occurred with Lc-Ecdy 8 (0.7 $\mathrm{mg} / \mathrm{ml}^{-1}$ ) and ajuC, where $\mathrm{LT}_{50}$ of 6.72 and 6.93 days, respectively, and $\mathrm{LT}_{90}$ of 10.19 and 10.28 days, respectively, were observed (Table 2). The course of mortality for $20 \mathrm{E}$ corresponded closely to the results obtained in the experiment for "Adults". 


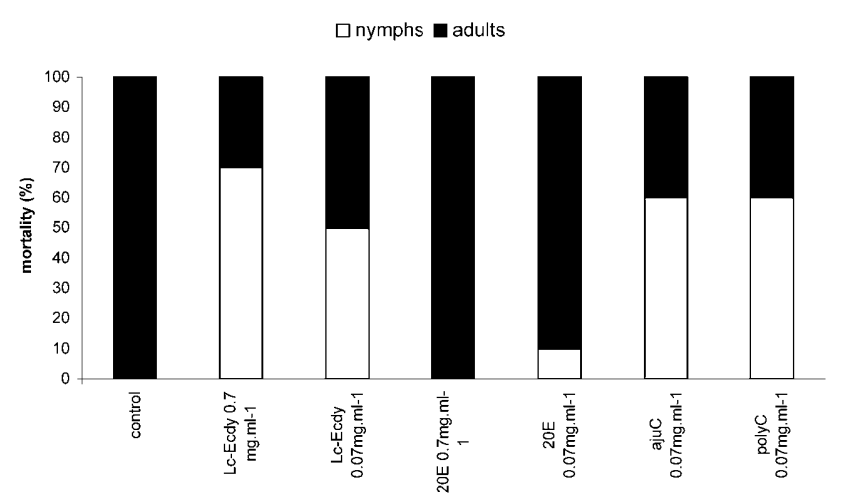

Fig. 2. The total mortality (in \%) of Brevicoryne brassicae distributed according to their developmental stages (nymphs + adults) when fed only as nymphs on treated plants ( $\Sigma$ all aphids is $100 \%$ ).

The ratios of larval and adult mortality in aphids that received ecdysteroids during the larval stage are presented in Figs 2 and 3. When the aphids fed on the plants treated with 0.07 or $0.7 \mathrm{mg} / \mathrm{ml}^{-1} 20 \mathrm{E}$, more than $85 \%$ of the test nymphs underwent development and natural mortality was observed only in the adult stage, the same as in the control group. When the aphids fed on plants treated with 0.07 or $0.7 \mathrm{mg} / \mathrm{ml}^{-1}$ Lc-Ecdy 8 , ajuC and polyB, mortality was observed, especially during nymphal stage development (60-100\%).

\section{Length of development and adult longevity} Nymphs

It was observed that the average longevity of aphids decreased with the concentration of the compounds. Aphids feeding on plants treated with Lc-Ecdy 8, ajuC and polyB during the nymphal stages (Table 3 ) showed a significant decrease in total longevity $\left(\mathrm{df}_{\mathrm{xy}}=6,63 ; \mathrm{F}=\right.$ $9.78, \mathrm{P}<0.0001$ ). The longevity ranged from 6.4 to 11.3 days after the introduction of cabbage aphids to the plants. No effect on longevity was observed with 0.07 and $0.7 \mathrm{mg} / \mathrm{ml}$ of the $20 \mathrm{E}$ (19.9 to 21.0 day). The untreated control exhibited an average longevity of 22.1 days.

\section{Adults}

The aphids feeding on plants treated with the ecdysteroids Lc-Ecdy 8, ajuC and polyB during their adult stages (Table 3 ) showed a significant decrease in total longevity $\left(\mathrm{df}_{\mathrm{xy}}=6,62 ; \mathrm{F}=5.87, \mathrm{P}<0.0001\right)$. The longevity ranged from 5.9 to 8.1 days after the introduction of cabbage aphids to the treated plants. No effect on longevity was observed with concentrations of 0.07 and $0.7 \mathrm{mg} / \mathrm{ml}$ of the 20E (11.3 to 13.7 day). The untreated control group exhibited an average longevity of 14.3 days.

Nymphs and adults

The aphids feeding on plants treated with the ecdysteroids Lc-Ecdy 8, ajuC and polyB during their nymphal and adult stages (Table 3 ) showed a significant decrease in total longevity $\left(\mathrm{df}_{\mathrm{xy}}=6,62 ; \mathrm{F}=13.42, \mathrm{P}<0.0001\right)$. The longevity ranged from 3.6 to 10.7 days after the introduc-

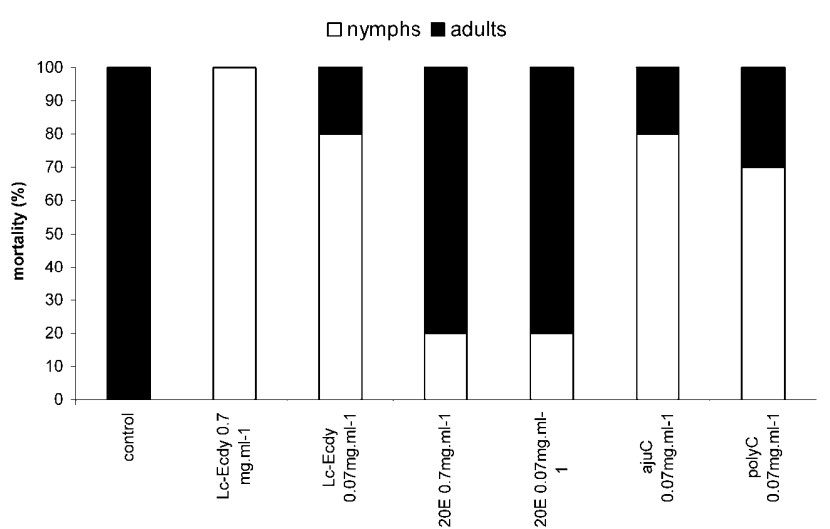

Fig. 3. The total mortality (in \%) of Brevicoryne brassicae distributed according to their developmental stages (nymphs + adults) when fed continuously during their whole life (nymphal and adult) on treated plants ( $\Sigma$ all aphids is $100 \%$ ).

tion of cabbage aphids to the treated plants. No effect on longevity was observed with the $20 \mathrm{E}$ (from 16.0 to 17.5 day). The untreated control group lived in average of 14.3 days.

\section{Fecundity}

Nymphs

The effect of ecdysteroids on fecundity is summarised in Table 3, expressed as the average number of offspring per female per day of the mature imago's life. The aphids feeding on plants treated with all of the ecdysteroids during their nymphal stages (Table 3 ) showed a significant decrease of average number of offspring per female $\left(\mathrm{df}_{\mathrm{xy}}=6,38 ; \mathrm{F}=7.13, \mathrm{P}<0.0001\right)$. The average number of offspring ranged from 1.2 to 2.7 nymphs per day for all ecdysteroids. In the control, the average number of offspring was 4.6 nymphs/day.

\section{Adults}

A significant effect $\left(\mathrm{df}_{\mathrm{xy}}=6,53 ; \mathrm{F}=6.80, \mathrm{P}<0.0001\right)$ on the number of offspring was observed with aphids feeding on plants treated solely with ecdysteroids during their mature stage (Table 3). This effect manifested itself by a significant decrease in fecundity at the concentration of $0.07 \mathrm{mg} / \mathrm{ml}$ of ajuC, when the average number of offspring was 1.0 nymphs/day. Other ecdysteroids had a significant effect (in addition Lc-Ecdy 8) on the number of offspring which ranged from 2.2 to 2.9 nymphs / day. In the control group, the average number of offspring was 4.6 day.

\section{Nymphs and adults}

A significant effect $\left(\mathrm{df}_{\mathrm{xy}}=5,35 ; \mathrm{F}=25.82, \mathrm{P}<\right.$ 0.0001 ) on the number of offspring was observed with aphids feeding on plants treated with ecdysteroids during their nymph and mature stages (Table 3 ). The effect of $20 \mathrm{E}$ on fecundity was almost equal to the effect observed in the treatment of aphids which fed only during their nymphal stages. The concentration of $0.07 \mathrm{mg} / \mathrm{ml}$ of ajuC and polyB showed the maximum effects in all experiments. 
TABlE 3. Effect of ecdysteroids on the development period and longevity of Brevicoryne brassicae (average periods in days \pm S.E.) $\mathrm{z}$ - at these doses it was not possible to determine the effect on the nymphal development and reproductive period due to high mortality; $\mathrm{y}$ - bold - nymphs and/or adults sucking only treated plants; italic - nymphs and/or adults sucking only plants not treated. $\mathrm{x}$ - within columns, figures followed by a common letter do not differ significantly at $P \leq 0.05$ (Tukey).

\begin{tabular}{|c|c|c|c|c|c|c|c|c|}
\hline \multirow{2}{*}{ Phytoecdysteroids } & \multicolumn{4}{|c|}{ Development } & \multirow{2}{*}{$\begin{array}{c}\text { Total nymphal } \\
\text { development }\end{array}$} & \multirow{2}{*}{$\begin{array}{l}\text { Longevity } \\
\text { of adults }\end{array}$} & \multirow{2}{*}{$\begin{array}{c}\text { Mean } \\
\text { longevity }\end{array}$} & \multirow{2}{*}{ Fecundity } \\
\hline & $1^{\text {st }}$ instar & $2^{\text {nd }}$ instar & $3^{\text {rd }}$ instar & $4^{\text {th }}$ instar & & & & \\
\hline \multicolumn{9}{|l|}{ Nymphs } \\
\hline Lc-Ecdy $8(0.7$ mg/ml $)$ & $2.2 \pm 0.42$ & $2.4 \pm 0.52$ & $2.0 \pm 0.00$ & $1.7 \pm 0.58$ & $8.3 \pm 0.58$ & $4.0 \pm 2.34 a$ & $6.4 \pm 4.50 \mathrm{a}$ & $1.2 \pm 1.08 \mathrm{a}$ \\
\hline Lc-Ecdy $8(0.07 \mathrm{mg} / \mathrm{ml})$ & $2.4 \pm 0.70$ & $2.3 \pm 0.46$ & $1.7 \pm 0.52$ & $1.7 \pm 0.52$ & $8.0 \pm 1.10$ & $8.0 \pm 6.75 a b$ & $10.2 \pm 7.64 \mathrm{a}$ & $2.2 \pm 2.11 \mathrm{a}$ \\
\hline $20 \mathrm{E}(0.7 \mathrm{mg} / \mathrm{ml})$ & $2.2 \pm 0.42$ & $2.2 \pm 0.42$ & $1.8 \pm 0.92$ & $1.9 \pm 0.57$ & $8.1 \pm 0.57$ & $12.9 \pm 7.53 a b$ & $21.0 \pm 7.36 \mathrm{c}$ & $2.5 \pm 0.42 \mathrm{a}$ \\
\hline $20 \mathrm{E}(0.07 \mathrm{mg} / \mathrm{ml})$ & $2.4 \pm 0.52$ & $1.8 \pm 0.42$ & $1.7 \pm 0.50$ & $2.2 \pm 0.44$ & $8.2 \pm 0.67$ & $13.6 \pm 6.93 a b$ & $19.9 \pm 8.76 b c$ & $2.7 \pm 0.56 \mathrm{a}$ \\
\hline $\mathrm{ajuC}(0.07 \mathrm{mg} / \mathrm{ml})$ & $1.8 \pm 0.42$ & $2.2 \pm 0.41$ & $2.3 \pm 0.50$ & $2.0 \pm 0.82$ & $8.5 \pm 1.00$ & $10.0 \pm 3.46 a b$ & $10.4 \pm 6.75 \mathrm{a}$ & $2.6 \pm 0.93 \mathrm{a}$ \\
\hline polyB (0.07 mg/ml) & $2.0 \pm 0.47$ & $2.1 \pm 0.32$ & $1.8 \pm 0.41$ & $2.2 \pm 0.45$ & $8.0 \pm 0.71$ & $10.8 \pm 8.18 a b$ & $11.3 \pm 3.83 \mathrm{ab}$ & $2.0 \pm 1.19 \mathrm{a}$ \\
\hline \multicolumn{9}{|l|}{ Adults } \\
\hline Lc-Ecdy $8(0.7$ mg/ml $)$ & $2.5 \pm 0.53$ & $2.2 \pm 0.42$ & $1.9 \pm 0.57$ & $1.9 \pm 0.32$ & $8.5 \pm 0.85$ & $6.3 \pm 3.77 \mathrm{a}$ & $14.8 \pm 4.02 a$ & $2.2 \pm 1.23 \mathrm{ab}$ \\
\hline Lc-Ecdy 8 (0.07 mg/ml) & $2.4 \pm 0.52$ & $1.7 \pm 0.48$ & $2.0 \pm 0.67$ & $1.9 \pm 0.57$ & $8.0 \pm 0.94$ & $6.7 \pm 3.62 \mathrm{a}$ & $14.7 \pm 3.59 a$ & $3.3 \pm 1.30 b c$ \\
\hline $20 \mathrm{E}(0.7 \mathrm{mg} / \mathrm{ml})$ & $2.3 \pm 0.48$ & $2.1 \pm 0.57$ & $1.6 \pm 0.70$ & $1.8 \pm 0.42$ & $7.8 \pm 0.92$ & $11.3 \pm 5.99 \mathrm{ab}$ & $16.9 \pm 6.93 a b c$ & $2.5 \pm 1.31 \mathrm{ab}$ \\
\hline $20 \mathrm{E}(0.07 \mathrm{mg} / \mathrm{ml})$ & $2.1 \pm 0.57$ & $1.8 \pm 0.42$ & $1.6 \pm 0.52$ & $1.9 \pm 0.57$ & $7.4 \pm 1.07$ & $13.7 \pm 4.42 \mathrm{~b}$ & $21.3 \pm 4.06 b c$ & $2.8 \pm 1.05 a b$ \\
\hline ajuC(0.07 mg/ml) & $2.1 \pm 0.57$ & $2.0 \pm 0.47$ & $1.9 \pm 0.32$ & $1.8 \pm 0.42$ & $7.8 \pm 0.92$ & $5.9 \pm 2.42 \mathrm{a}$ & $13.7 \pm 2.45 a$ & $1.0 \pm 0.72 a$ \\
\hline polyB $(0.07 \mathrm{mg} / \mathrm{ml})$ & $1.9 \pm 0.57$ & $2.0 \pm 0.47$ & $2.0 \pm 0.47$ & $2.1 \pm 0.32$ & $8.0 \pm 0.94$ & $8.1 \pm 3.28 \mathrm{a}$ & $16.1 \pm 3.93 a b$ & $2.9 \pm 1.10 \mathrm{ab}$ \\
\hline \multicolumn{9}{|l|}{ Nymphs and adults } \\
\hline Lc-Ecdy $8(0.7$ mg/ml $)$ & $2.6 \pm 0.53$ & $1.8 \pm 0.75$ & $1.5 \pm 0.58$ & $-\mathbf{z}$ & - & - & $3.6 \pm 1.58 \mathrm{a}$ & - \\
\hline Lc-Ecdy 8 (0.07 mg/ml) & $2.1 \pm 0.57$ & $1.8 \pm 0.42$ & $2.0 \pm 0.58$ & $2.0 \pm 0.00$ & $7.5 \pm 0.58$ & $9.5 \pm 0.58 \mathrm{ab}$ & $9.5 \pm 4.30 \mathrm{ab}$ & $3.0 \pm 0.06 b c$ \\
\hline $20 \mathrm{E}(0.7 \mathrm{mg} / \mathrm{ml})$ & $2.1 \pm 0.32$ & $2.0 \pm 0.47$ & $1.6 \pm 0.52$ & $1.8 \pm 0.42$ & $7.5 \pm 0.97$ & $10.9 \pm 4.67 \mathrm{ab}$ & $16.0 \pm 6.58 \mathrm{bcd}$ & $2.4 \pm 0.77 b$ \\
\hline $20 \mathrm{E}(0.07 \mathrm{mg} / \mathrm{ml})$ & $2.3 \pm 0.48$ & $2.0 \pm 0.00$ & $1.5 \pm 0.53$ & $1.9 \pm 0.64$ & $7.8 \pm 0.71$ & $13.8 \pm 5.78 b$ & $17.5 \pm 9.06 \mathrm{~cd}$ & $2.3 \pm 1.29 b$ \\
\hline ajuC(0.07 mg/ml) & $2.0 \pm 0.47$ & $2.1 \pm 0.38$ & $2.0 \pm 0.89$ & $2.3 \pm 0.52$ & $7.7 \pm 1.03$ & $5.3 \pm 2.73 \mathrm{a}$ & $7.3 \pm 4.60 \mathrm{a}$ & $0.8 \pm 0.79 a$ \\
\hline polyB $(0.07 \mathrm{mg} / \mathrm{ml})$ & $2.0 \pm 0.47$ & $2.1 \pm 0.38$ & $1.8 \pm 0.50$ & $2.3 \pm 0.52$ & $7.3 \pm 0.52$ & $10.7 \pm 0.52 \mathrm{ab}$ & $10.7 \pm 5.62 \mathrm{abc}$ & $0.1 \pm 0.05 a$ \\
\hline Control & $2.0 \pm 0.47$ & $1.9 \pm 0.32$ & $2.0 \pm 0.47$ & $1.9 \pm 0.57$ & $7.8 \pm 0.79$ & $14.3 \pm 4.11 b$ & $22.1 \pm 4.09 d$ & $4.6 \pm 0.96 c$ \\
\hline
\end{tabular}

\section{DISCUSSION}

The results of bioassays with phytoecdysteroids applied systemically through the roots of rape plants showed significant differences in the mortality and fecundity of $B$. brassicae feeding on the plants. Our results thus confirmed the applicability of previously published methods (Gelbič et al., 1984; Melé et al., 1992; Pavela et al., 2004) for systemic application of compounds through the conducting plant tissues for testing the efficacy of compounds on sucking insects. Phytoecdysteroids are chemically quite stable in a water solution, especially under the neutral conditions which were used for our experiments. They are well accepted and translocated in plant tissues (Melé et al., 1992) and they do not cause changes in the metabolism or in the hormonal activity of plants (Macháčková et al., 1995).

The role of ecdysteroids in the life-cycle of plants has not been elucidated so far. There still exist two main hypotheses. According to the first one, phytoecdysteroids may have a hormonal role in the plant, but there is very little evidence supporting this hypothesis and quite a lot against it (Macháčková et al., 1995; Dinan et al., 1998). Alternatively, it has been recognized for a long time that phytoecdysteroids possessing insect moulting hormone activity could participate in the defence of plants against non-adapted phytophagous invertebrates (Dinan, 2001). Our results provide corroborative evidence for this hypothesis. Nevertheless, a rather high variability in the effect of single ecdysteroids was observed.

The systemic application of low concentrations of ajugasterone $\mathrm{C}$ (ajuC) and polypodine $\mathrm{B}$ (polyB), as well as the crude crystalline ecdysteroid fraction 8 (Lc-Ecdy 8), to the plants caused a significant increase in mortality and a reduction in longevity of cabbage aphids. The majority of aphids fed on plants treated with ajuC, polyB or LCEcdy 8 did not complete their development and died in the juvenile stage (Figs 2 and 3). However, 20hydroxyecdysone (20E) did not significantly affect the development of nymphs. A slight increase in mortality was observed only in adult aphids. This may support the assumption that insects are generally more adapted to 
major plant constituents than to their less abundant analogues or chemically transformed derivatives with a feasible phytoalexin-like feature. Melé et al. (1992) obtained similar results with the nymphs of the whitefly, Trialeurodes vaporariorum. The authors tested the mortality of selected ecdysteroids isolated from the Ajuga reptans plant on the development and longevity of $T$. vaporariorum. Similar to our experiments, the ecdysteroids did not cause changes during the nymphal developmental period. Significant differences in mortality were observed with single ecdysteroids, where the highest mortality was detected especially in the first instar period, particularly with 29-norsengosterone, 29-norcyasterone and polypodine-B. Identical to our results, they did not observe significant mortality for $20 \mathrm{E}$. The authors have also proven that the ecdysteroids were translocated from the culture medium to the leaf with no apparent changes in their composition.

From the chemical structure-biological activity relationship point of view, it is interesting that ajuC and polyB, hydroxylated in rather unusual positions (C-5 or C-11), show significantly higher activity than $20 \mathrm{E}$, the compound with substituents in normal positions for ecdysteroids. The minimum $35.8 \%$ content of unusually substituted ecdysteroids (including makisterone A and inokosterone) in crystalline fraction Lc-Ecdy 8 caused this fraction to show high activity, only slightly influenced by the $45.4 \%$ content of $20 \mathrm{E}$. For a further study of this structure-activity relationship we are now testing other ecdysteroids containing usual and unusual skeletal or side-chain substituents.

The biological activity of some phytoecdysteroids has been tested in a wide variety of insect bioassays (Bergamasco \& Horn, 1980; Cymborovski, 1989; Dinan, 2001). Almost all phytoecdysteroids demonstrate quantifiable activity on the ecdysteroid receptor (Dinan et al., 1999) and are used for quantitative structure - activity relationship studies to explain the rather high variability of their effects (Harmatha \& Dinan, 1997). Ecdysteroids have also been reported to affect insect growth and reproduction in vivo, when added to natural or artificial diets which would otherwise support optimum growth and reproduction (Sláma et al., 1993; Zhang \& Kubo, 1994; Dinan, 2001). When comparative efficacy tests of $20 \mathrm{E}$ were done with other ecdysteroids, the results always displayed higher biological activity of the other ecdysteroids than 20E (Arnault \& Sláma, 1986; Melé et al., 1992). Our systemic application expanded these studies to aphids. Even though our experiments were made with a small sample of aphids (mainly because of insufficient availability of pure ecdysteroids), it was possible to conclude that the systemic application of $20 \mathrm{E}$, ajuC and polyB, likewise an ecdysteroid mixture (fraction Lc-Ecdy 8), in low concentrations caused significant mortality and also significantly increased the reduction of fertility. The observed reduction of aphid fertility in our experiments was probably due to the disturbance of hormonal balances that may consequently affect the population dynamics of
B. brassicae aphids. However, antifeeding or metabolic inhibition effects should not be excluded.

ACKNOWLEDGEMENT. This work was supported by Czech Ministry of Agriculture, Project No. MZE 0002700603 and by GA ČR grant No. 203/04/0298.

\section{REFERENCES}

AdLer J.H. \& GRebenoK R.J. 1999: Occurrence, biosynthesis, and putative role of ecdysteroids in plants. Critical Rev. Biochem. Molec. Biol. 34: 253-264.

Arnault C. \& Sláma K. 1986: Dietary effects of ecdysteroids in the leek-moth, Acrolepiopsis assectella Zell. (Lepidoptera: Acrolepiidae) J. Chem. Ecol. 12: 1979-1986.

Bergamasco R. \& Horn D.H.S. 1980: The biological activities of ecdysteroids and ecdysteroids analogs. In Hoffmann J.A. (ed.): Developments in Endocrinology 7. Progress in Ecdysone Research. Elsevier, Amsterdam, pp. 299-324.

Bergamasco R. \& Horn D.H.S. 1983: Distribution and role of insect hormones in plants. In Downer R.G.H. \& Laufer H. (eds): Invertebrate Endocrinology. Endocrinology of Insects 1. Alan R. Liss, New York, pp. 627-654.

CAMPS F. 1991: Plant ecdysteroids and their interaction with insects. In Harborne J.B. \& Tomas-Barberan F.A. (eds): Ecological Chemistry and Biochemistry of Plant Terpenoids. Clarendon Press, Oxford, pp. 331-376.

Cymborovski B. 1989: Bioassays for ecdysteroids. In Koolman J. (ed.): Ecdysone: From Chemistry to Mode of Action. Georg Thieme Verlag, Stuttgart, pp. 144-149.

Dinan L. 2001: Phytoecdysteroids: biological aspects. Phytochemistry 57: 325-339.

DinAN L. 2004a: Literature reports - occurrence of ecdysteroids. In Lafont R., Harmatha J., Marion-Poll F., Dinan L., Wilson I.D. (eds): The Ecdysone Handbook. 3rd ed. On-line http://ecdybase.org

DinAN L. 2004b: Literature reports - activities of ecdysteroids. In Lafont R., Harmatha J., Marion-Poll F., Dinan L., Wilson I.D. (eds): The Ecdysone Handbook. 3rd ed. On-line http://ecdybase.org

Dinan L., Whiting P. \& Scott A. 1998: Taxonomic distribution of phytoecdysteroids in seeds of members of the Chenopodiaceae. Biochem. Syst. Ecol. 26: 553-576.

Dinan L., Hormann R.E. \& Fujimoto T. 1999: An extensive ecdysteroid CoMFA. J. Computer-Aided Molec. Design 13: 185-207.

Galbraith M.N. \& Horn D.H.S. 1966: An insect-moulting hormone from plant. J. Chem. Soc. Chem. Commun. 24: 905-906.

Gelbič I., Tonner M. \& HolÝ A. 1984: Aphid sterility induced by antiviral agent (RS)-9-(2,3 dihidroxypropyl) adenine. Acta Entomol. Bohemoslov. 81: 46-53.

HaRmatha J. \& Dinan L. 1997: Biological activity of natural and synthetic ecdysteroids in the B-II bioassay. Arch. Insect Biochem. Physiol. 35: 219-225.

Jizba J., Herout V. \& Šorm F. 1967: Isolation of ecdysterone (crustecdysone) from Polypodiun vulgare L. rhysomes. Tetrahedron Lett. 18: 1689-1691.

LAFONT R. 1998: Phytoecdysteroids in world flora: diversity, distribution, biosynthesis and evolution. Russ. J. Plant Physiol. 45: 276-295.

Lafont R., Bouthier A. \& Wilson I.D. 1991: Phytoecdysteroids: structures, occurrence, biosynthesis and possible ecological significance. In Hrdý I. (ed.): Insect Chemical Ecology. Academia Prague and SPB Academic Publishing, The Hague, pp. 197-214. 
Lafont R., Harmatha J., Marion-Poll F., Dinan L. \& Wilson I.D. 2002: The Ecdysone Handbook. 3rd ed. On-line http://ecdybase.org

MacháČKovÁ I., VÁgNer M. \& Sláma K. 1995: Comparison between the effects of 20-hydroxyecdysone and phytohormones on growth and development in plants. Eur. J. Entomol. 92: 309-316.

Melé E., Messeguer J., Gabarra R., Tomás J., Coll J. \& Camps F. 1992: In vitro bioassay for the effect of Ajuga reptans phytoecdysteroids on Trialeuroides vaporariorum larval development. Entomol. Exp. Apl. 26: 163-168.

Nakanishi K., Koreeda M., Sasaki S., Chang M.L. \& Hsu H.Y. 1966: The structure of ponasterone A an insect moulting hormone from the leaves of Podocarpus nakaii hay. J. Chem. Soc. Chem. Commun. 24: 915-917.

Pavela R., Bárnet M. \& Kocourek F. 2004: Effect of azadirachtin applied systemically through roots of plants on the mortality, development and fecundity of the cabbage aphid (Brevicoryne brassicae). Phytoparasitica 32: 286-294.
Píš J., Buděšínský M., Vokáč K., Laudová V. \& Harmatha J. 1994: Ecdysteroids from the roots of Leuzea carthamoides. Phytochemistry 37: 707-711.

Sláma K., Abubakirov N.K., Gorovits N.B., Baltaev U.A. \& SAATOV Z. 1993: Hormonal activity of ecdysteroids from certain Asiatic plants. Insect Biochem. Mol. Biol. 23: 181-185.

VoKÁČ K., BudĚŠínsKÝ M. \& Harmatha J. 2002: Minor ecdysteroid components of Leuzea carthamoides. Collect. Czech. Chem. Commun. 67: 124-139.

Zelený J., Havelka J. \& Sláma K. 1997: Hormonally mediated insect-plant relationships: Arthropod populations associated with ecdysteroid-containing plant, Leuzea carthamoides (Asteraceae). Eur. J. Entomol. 94: 183-198.

Zhang M.I. \& KuBo I. 1994: Mechanisms of Heliothis virescens resistance to exogenous ecdysteroids. ACS Symposium Series 557: 182-201.

Received February 16, 2005; revised and accepted May 25, 2005 